\title{
Urgences
}

\section{Mémoire de peau}

\section{Esther Loiselle}

Numéro 29, octobre 1990

\section{Éclats d'œuvre}

URI : https://id.erudit.org/iderudit/025603ar

DOI : https://doi.org/10.7202/025603ar

Aller au sommaire du numéro

\section{Éditeur(s)}

Urgences

\section{ISSN}

0226-9554 (imprimé)

1927-3924 (numérique)

Découvrir la revue

\section{Citer ce document}

Loiselle, E. (1990). Mémoire de peau. Urgences, (29), 54-55.

https://doi.org/10.7202/025603ar d'utilisation que vous pouvez consulter en ligne.

https://apropos.erudit.org/fr/usagers/politique-dutilisation/ 


\section{FRAGMENTATIONS}




\section{Mémoire de peau}

\section{Esther Loiselle}

La claustration. Il y a de cela. Un peu. Dans le presque silence de ma retraite, que des livres grand ouverts et moi à la recherche du mot de passe. Je furète, lis une phrase, opine; puis une autre, je m'en veux de ne l'avoir pas écrite. Mes doigts: hélas! que n'en ai-je davantage. Dix pitoyables signets entre lesquels déborde le sens. Un trop-plein. Je lâche prise, range les titres.

Le repli. Je me reprends, me ravine, mets à nu les strates de ma mémoire, puis les soulève, une à une, délicatement de peur qu'elles ne s'étiolent. Elles apparaissent alors, ces empreintes toutes miennes, vieillies mais chaudes pourtant de la vie qui les a faites; elles-mêmes mères en radicelles comme la vie qu'elles ont forgée. Je suis rhizome, mes sens l'affirment, leurs empreintes l'exhalent, et dans le repli, de moi sur moi, je scrute ce qu'ils m'ont laissé de mémoire. C'est ainsi que le plus souvent je puise mes débuts, celui-ci et tous les autres encore, au mien propre.

Mais le repli s'épuise. Ou bien je m'épuise dans le repli. D'ailleurs, je suis distraite. Par goût. Je résiste mal aux digressions et là où elles semblent absentes, je les crée. J'abandonne volontiers au silence de mon repaire le soin de veiller sur la mémoire de mes racines. L'autre, sensuelle, viendra la nourrir. Revenu le temps de la nécessaire solitude, je saurai alors nommer le sillon nouveau.

Je m'abandonne. Entre mes doigts, une rose fraîchement coupée. Saurai-je jamais la narrer: sortis les harpons de la tige guerrière casquée du carmin de ses pétales aux abords déployés, resserrement des sinus vers son centre, tout de replis, comme moi avant. Jy plonge le nez: l'intrus se souvient. Legs d'une mémoire de rose. Maintenant il m'en souvient: jamais je ne saurai la dire. Le prétendre serait une méprise: la fugacité ne se conte pas, elle émeut. Les délices de l'éphémère sont tels parce que non dits et les mots sont à l'avance vaincus qui tentent de s'y ajuster. Tout au plus, par approximations successives, me rendent-ils parfois à ce qui fut un instant de grâce.

Pulsion intime. Mes sens réclament la mise en forme de la mémoire qu'ils enfantent. Jécris. Mes mots sont faits de 
traces, celles inscrites dans ma chair, déjà, celles à venir, aussi. Pour l'heure, je me mets à l'œuvre, ne la fais pas. Je travaille au déploiement de la digression, dans ce qu'elle permet de rapprochement entre les choses et ce qu'il m'en reste. L'écriture, la mienne, témoigne de ce reste et de lui seul. Elle est, en ce sens, le dire de l'inessentiel. Les choses ne m'attendent pas, ne l'ont jamais fait. Elles se donnent, révèlent leurs charmes singuliers. Je les prends, crois les nommer; mais toujours mes mots n'embrassent-ils que leurs pourtours; mots en marge. Je travaille à coder le flanc des choses, je serre au plus près leurs formes, elles m'échappent. Parole muette, infiniment. Je saurai ailleurs reconnaître son intaille dans ma peau, le sillon nouveau. 